\title{
Study on the effect of solid properties on the hydrodynamics in an ebullated Bed reactor
}

\author{
Luma H. Mahmod*, Amer A. AbdulRahman* and Mohammad F. Abid***** \\ * Department of Chemical Engineering, University of Technology, PO. Box: 35010, Baghdad, Iraq. \\ ** Department of Oil \& Gas Refining Engineering, Al-Turath University College, Al-Mansour Quarter, Baghdad, Iraq. \\ *** Corresponding Author: mohammad.fadhil@turath.edu.iq
}

Submitted : 15/08/2020

Revised :05/06/2021

Accepted :25/07/2021

\begin{abstract}
Published data on the hydrodynamics of ebullated- bed reactors (EBRs) used in the H-Oil process are scarce. In the present work, the effect of solid properties (e.g., particle size, and degree of hydrophobicity) on the hydrodynamics and foaminess in a lab-scale cold model of an (EBR) was investigated. 20wt. \% MgSO4 solution was utilized as the liquid phase to imitate the hydrodynamic trends in the industrial-scale EBR of the hydro-conversion process. Experimental results depicted that the flow regime of the multiphase system can be readily evaluated by using the pressure drop technique. The turning from the bubbly to the turbulent system is enhanced with diminishing particle size, and decreasing particle hydrophobicity. Moreover, the degree of particle hydrophobicity was inversely proportional to the average gas holdup in the EBR. The reduction in average gas holdup was $7.9 \%$ using hydrophobic particles more than that of the hydrophilic one. In the EBR, it was found that bubble sizes were increased with both gas velocity and the axial location far from the gas distributor while liquid velocity has negative impact on bubble size. The experimental work revealed that hydrophobic particles of smaller size (250 $\mu \mathrm{rm}$ ) reduced foaming by $70 \%$ using 20 vol. \% of solid loading and gas and liquid velocities of 10 and $0.15 \mathrm{~cm} \mathrm{~s}^{-1}$, respectively. This outcome revealed that the surface of catalyst particles used can be modified to act as foaminessreducer in fluidized bed hydro conversion reactors.
\end{abstract}

Keywords: H-Oil process; Ebullated bed reactor; Hydrophobicity; Gas holdup; Foaming.

\section{INTRODUCTION}

The ebullated bed reactor (EBR) is one of the newest types of reactors that are used in the hydrogenation of heavy oils that contain high amounts of sediments, asphaltenes, and metals (Zhang and Shaw, 2006). The reactor is characterized by many virtues such as the ability to add and empty the catalyst from it without stopping work. In addition, the spread of the catalyst particles in reactor prevents the blockage of the fluid pathways with asphaltic materials and helps to increase the mixing between the reactants and reduces the temperature difference between the parts of the reactor, which makes its behavior similar to the continuous mixing reactor (Kressmann et al., 2000). The most common application is the hydrodesulfurization and hydrocracking of vacuum residue (H-Oil process) (Martı'nez et al., 2010). A schematic of an EBR is shown in Figure 1. 


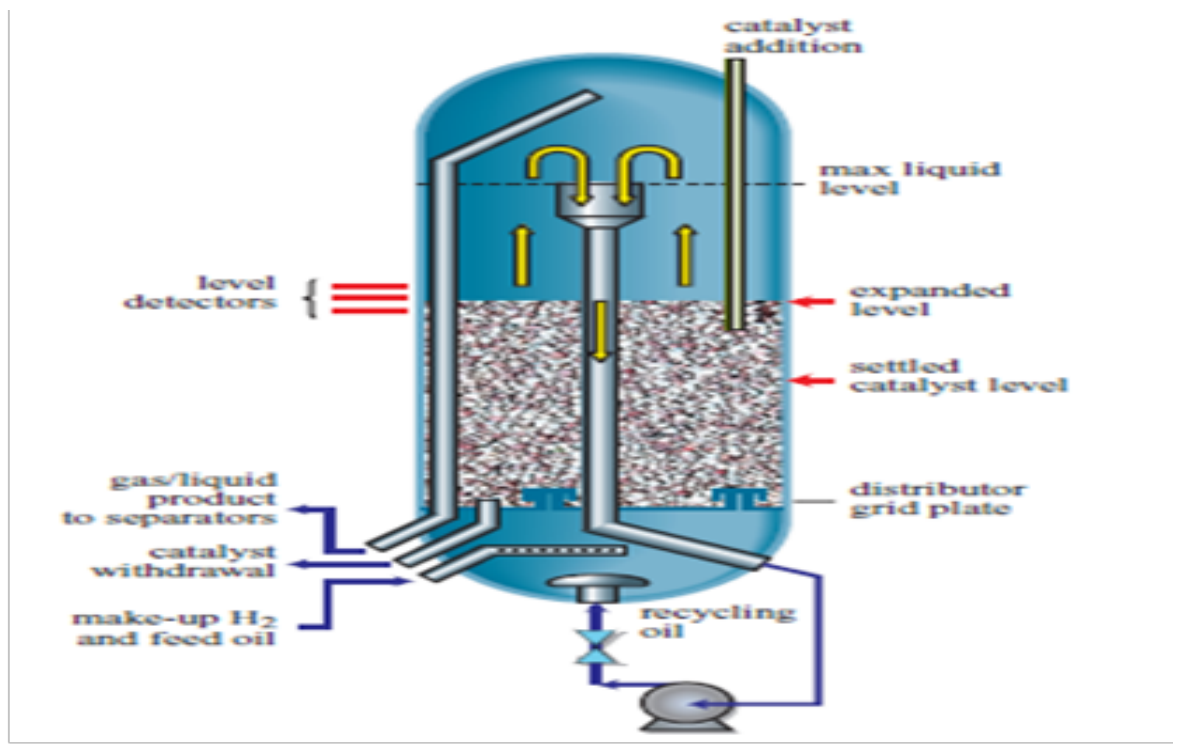

Figure1. Ebullated bed reactor system.

The catalysts for the EBR process are similar in composition with those in the fixed bed system except for the pellet size which is typically lesser than $1 \mathrm{~mm}$ to help the catalyst particles in fluidization by the upward- flow liquid within the reactors. However, the catalysts used have a different degree of hydrophobicity which may affect the hydrodynamic parameters in the reactor. The activity and efficacy of the hydro-processing ebullated bed reactor are extremely dependent upon the operating conditions and bed hydrodynamics. In general, the scale-up of EBRs depends on the estimation of the phenomena of mixing, mass and heat transfer, and chemical kinetics of the reacting system (Schweitzer and Kressmann, 2004; Herbolzheimer et al., 2006). The Interrelation of the gas holdup घg with the pressure drop $\Delta \mathrm{P}$ along with the bed rising $\Delta \mathrm{H}$ in a three-phase slurry bubble column has been described by Abid et al. (2019) as follows:

$$
\varepsilon_{\varepsilon}=1-\frac{1}{g\left(\rho_{l} \varepsilon_{l}+\rho_{i} \varepsilon_{i}\right)} \frac{\Delta P}{\Delta H}
$$

where $\varepsilon_{l}$ is the holdup of liquid, $\varepsilon_{\mathrm{s}}$ the holdup of particles, $\rho_{1}$ liquid density, and $\rho_{\mathrm{P}}$ particle density. With rising superficial gas velocity, gas holdup rises also, with fewer effect in the turbulent system than in the bubbly system, and many published data depicted these conclusions (Jordan, and Schumpe, 2001; Behkish et al., 2002; Vandu et al., 2004; Lau et al., 2004, Chaumat et al., 2005; Lang, 2002). Lau et al. (2004) found that the improvement of mass transport at higher liquid velocities is almost certainly due to the turbulence induced by the liquid stream and the effect of the liquid velocity on gas holdup becomes more effective at soaring pressure. The influence of solid loading on gas holdup has been examined by many researchers (Sada et al., 1984; Pino et al., 1992). The authors reported that an increase in solids loading usually minimizes the gas holdup. (Chilekar (2007) and Chilekar et al. (2007) studied experimentally and theoretically the influence of column dimensions, solid particle properties, liquid properties, and column pressure on the hydrodynamics and mass transfer of a slurry bubble column (SBC). The authors used different column diameters $(11,15,19$ and $29 \mathrm{~cm})$, pressure from 1 to 13 bar, silica and carbon used as solid particles, and deionized water (aqueous) or Isopar- $\mathrm{M}$ oil or sodium gluconate utilized as an electrolyte. Chilekar (2007) revealed that the mass transfer coefficient and gas holdup have a direct positive relationship in a certain gas-liquid system. Chilekar et al. (2007) reported that the hold-up of gas and the point of transition from bubbly to churn mode are not affected by the existence of lyophilic particles and pressure applied. Foaming is 
considered undesirable in the reactors used for hydro carbonaceous fluid processing because foaming reduces the space required for chemical conversion. Antifoam agents have been used to control foaming (Andrew, 1982; Koide et al., 1985). Various designs of mechanical breakers have been also used to control foaming (Ghildyal et al., 1988; Takesono et al., 2004). Hydrophobic particles have been used to control foaming in an ethanol Iwaterlair mixture flowing into a vertical pipe at ambient conditions (Mata and Joseph, 1999). Published data are scarce of using particle hydrophobicity, for controlling foaming in hydro conversion reactors operated at severe conditions of temperature and pressures. The main objective of the current study was to investigate the influence of the degree of particle hydrophobicity on gas holdup, and axial solid distribution in a cold model of an ebullated bed reactor. Another objective was studying the foaming restrain under the effect of particle hydrophobicity in the EBRs.

\section{MATERIALS AND METHODS}

Table 1 shows the specifications of the solid particles utilized. Table 2 lists the detailed properties of the chemicals used.

Table 1. Sand particle specifications.

\begin{tabular}{|c|c|c|c|}
\hline $\begin{array}{c}\text { Av. particle size } \\
(\boldsymbol{\mu m})\end{array}$ & $\boldsymbol{U}_{\boldsymbol{m} \boldsymbol{f}\left(\mathbf{c m ~ s}^{-\mathbf{1}}\right)}$ & $\boldsymbol{U}_{\boldsymbol{t}}\left(\mathbf{\mathbf { c m ~ s } ^ { - 1 } )}\right.$ & $\begin{array}{c}\text { Particle density } \\
(\mathbf{g} / \mathbf{c c})\end{array}$ \\
\hline $\mathbf{2 5 0}$ & 0.153 & 9.25 & 2.45 \\
\hline $\mathbf{5 0 0}$ & 0.345 & 13.35 & 2.45 \\
\hline $\mathbf{8 0 0}$ & 0.672 & 17.25 & 2.45 \\
\hline
\end{tabular}

Table 2. Properties of the chemicals used

\begin{tabular}{|c|c|c|c|c|c|}
\hline Chemical & Purity $\%$ & M.wt. & Density $\left(\mathrm{g} \mathrm{cc}^{-1}\right)$ & Boiling pt. $\left({ }^{\circ} \mathrm{C}\right)$ & Supplier \\
\hline Butanol & 99 & 74.12 & 0.77 & 83 & AG Hasenstab-Riedel \\
\hline Octanol & 99 & 130.23 & 0.824 & 195 & Antares Chem. Co. \\
\hline $\mathrm{MgSO}_{4}$ powder & 99 & 120.27 & 2.66 & ----- & Laizhou Xinhe Chemicals \\
\hline
\end{tabular}

\section{METHODS}

The primary device for this study was an $82 \mathrm{~mm}$ outside diameter, $5 \mathrm{ml}$ thickness column, and $2.0 \mathrm{~meter}$ high. A schematic diagram and a photographic snapshot are shown in Figures 2, and 3 respectively. The column was made of acrylic (Plexiglas) to obtain clear observation for the bubbles generation and bed expansion during operation. Air and liquid admitted at the bottom of the column in the pre-mix region below the bed support. The gas sparger and the pre-mix area were not geometrically comparable to those in the industrial hydrocracker. This pre-mix region was charged with plastic ranching rings to improve the mixing of gas and liquid. To provide the column with the gas-phase, an air compressed bottle with a pressure regulator was used. Solid particles of the bed were raised by the up-flow rates of liquid and gas which keep this ebullated bed in random mixing. The liquid and gas are well regulated using calibrated flow meters of liquid and gas. At the top of the column, a recycle cup was installed which facilitates the returning of part of the up-flow liquid to the bottom of the column through a pipe of $25 \mathrm{~mm}$ diameter connected to a recirculation pump which mainly responsible for bed ebullition through the column. At the 
top of the column, liquid and air were guided to a 100-L PVC vessel supplied with gas vent. This vessel was used as the liquid feeding source to the column. A solution of $20 \mathrm{wt} . \% \mathrm{MgSO}_{4}$ is used as the liquid phase in the current work, to simulate the viscosity and density of vacuum residue at the operating conditions of EBRs in the H-Oil process (Safoniuk, 1999). The cold model column supplied with 6- pressure tapes situated axially along the column. Separately, all the taps were joined to a pressure gauge $(0-1.50$ bar $)$ to calculate local pressure within the column. Foaming experiments were performed using a liquid-phase of $1 \mathrm{wt} . \%$ butanol as a surfactant. To design and operate the perforated plate (gas sparger) in such a way that a stable flow occurs, through all the perforations, and the procedure given by Ruff et al. (1976) and Mersmann (1978) were followed by the current work. Fig. 4(a) and Fig. 4(b) represent a schematic diagram of the lab-scale ebullated bed column and the perforated plate gas sparger respectively.

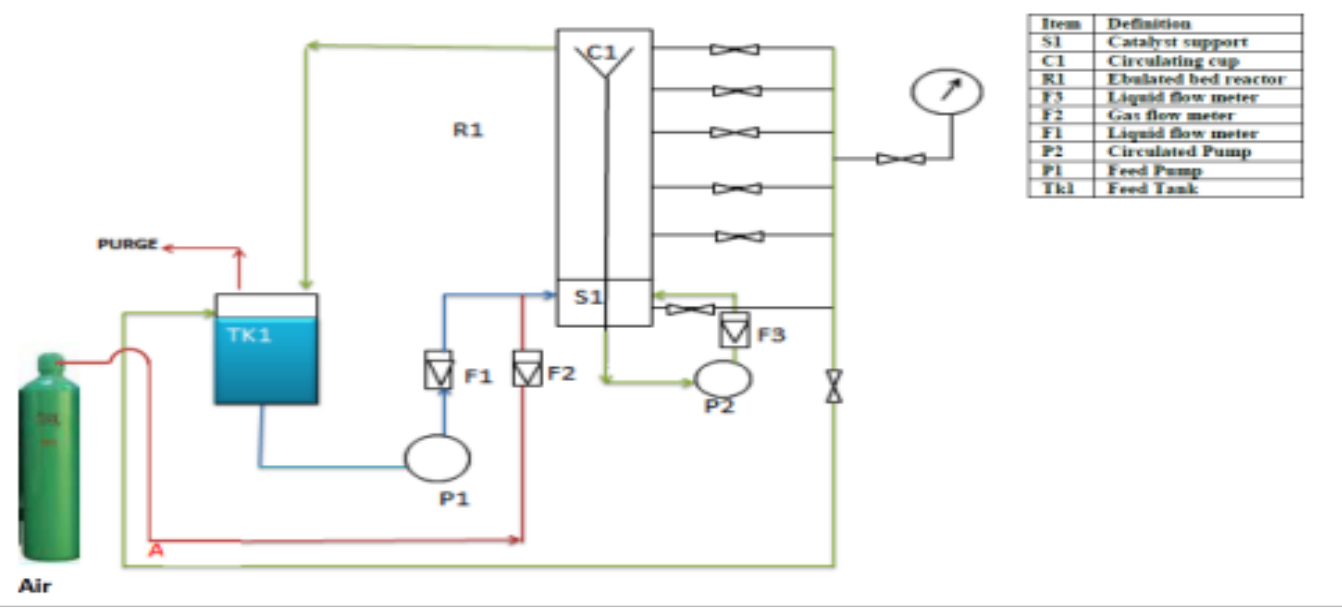

Figure 2. Experimental set up model.

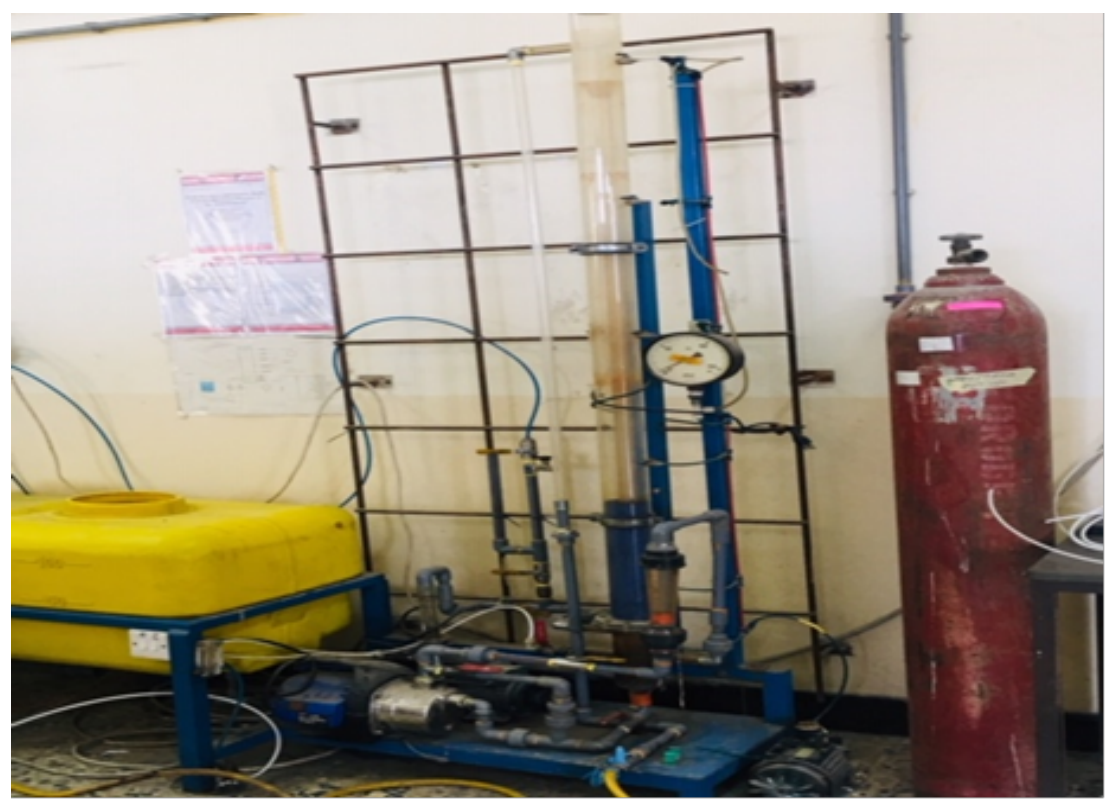

Figure 3. Experimental set up photographic view. 


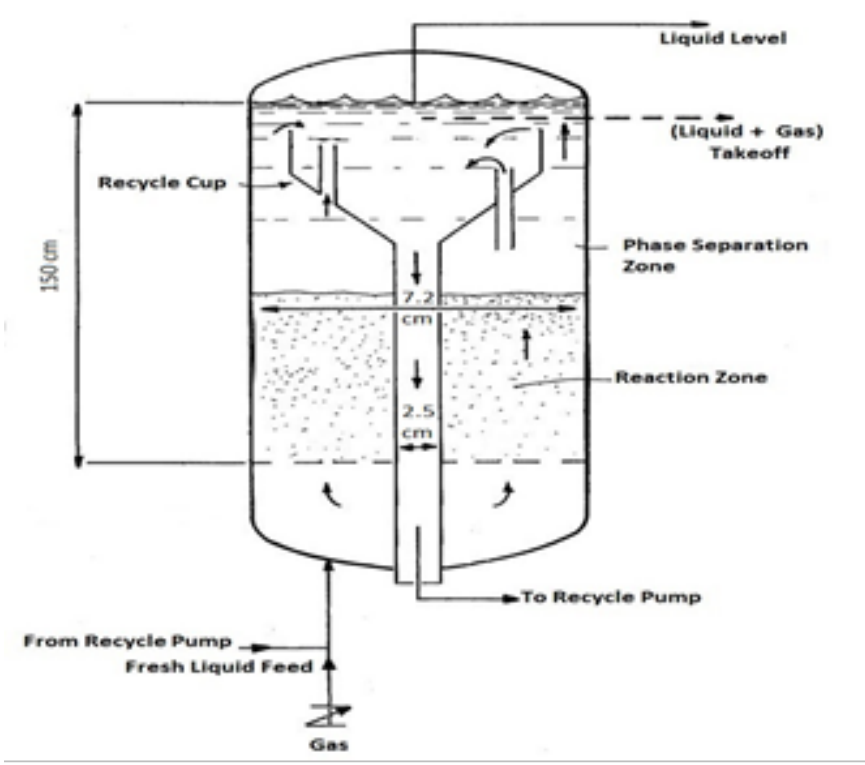

(4a)

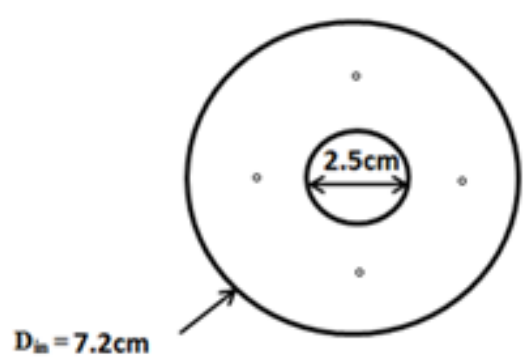

(4b)

Figure 4. (a) Schematic diagram of Lab-Scale EBR and (b) Perforated plate gas distributor.

In the current work, the hydrophilic sand particles turned into hydrophobic applying the procedure of (Maloney and Oakes, 1984). A hydrophobic alcohol was mixed with solid particles. The liquid-solid combination was heated at $165{ }^{\circ} \mathrm{C}$ for $4 \mathrm{hrs}$. This process was adequate for the silica to chemically respond considerably with octanol. In the present study, a simple technique proposed by Maloney and Oakes (1984) was used to check the degree of hydrophobicity of processed sand particles. In case untreated sands were poured in a bottle of water, it will drop freely to the bottom of the bottle. However, if a similar procedure was followed by hydrophobic sands, a diverse trend can be observed. Many particles floating over the water surface although their densities are more than $1 \mathrm{~g}$ $\mathrm{mL}-1$; the rest of particles drop to the base in big collective enclosed with a slight layer of air.

\section{EXPERIMENTAL DESIGN}

Factorial design technique was used in the present work to plan the experiments due to its consistency in find out the interactions between the operating parameters. The controlled variable real values $(F)$ and their equivalent levels $(\mathrm{L})$ are listed in Table 3. The recycle ratio $(\mathrm{R})$ in the ebullated bed reactor was constant at $\mathrm{R}=5$ for all experiments. All experiments were performed under ambient conditions (i.e., atmospheric pressure and $25^{\circ} \mathrm{C}$ ).

Table 3. Operating variables with their levels.

\begin{tabular}{|c|c|c|c|c|}
\hline \multirow{2}{*}{$\mathrm{F}$} & \multicolumn{4}{|c|}{ Real variables } \\
\cline { 2 - 5 } & $\begin{array}{c}\text { Av. Particle size } \\
(\mu \mathrm{m})\end{array}$ & $\begin{array}{c}\text { Liquid flow rate } \\
\left(\mathrm{L} \mathrm{min}^{-1}\right)\end{array}$ & $\begin{array}{c}\text { Gas flow rate } \\
\left.(\mathrm{L} \mathrm{min})^{-1}\right)\end{array}$ & $\begin{array}{c}\text { Solid loading } \\
(\mathrm{v} / \mathrm{v}) \%\end{array}$ \\
\hline 1 & 250 & 0.7 & 18 & 0 \\
\hline 2 & 500 & & 36 & 10 \\
\hline 3 & 800 & 1.4 & 55 & 20 \\
\hline
\end{tabular}




\section{RESULTS AND DISCUSSION}

\section{HYDROPHOBICITY AND SOLID PARTICLES SIZE EFFECT ON GAS HOLDUP}

The effects of five operating variables (i.e. gas velocity, particle hydrophobicity, loading of particles and particle size) on the gas holdup are investigated through the experimental runs. For the multiphase system, El-Din and Smith (2003) identified the behavior of a bubbly-churn regime as a function of an increase in gas velocity, using local gas holdup measurements which helped too much in determining those regimes with the height of the ebullated bed column. Figures 5, 6, and 7 illustrate the effect of gas velocity on the holdup of the gas-phase along the column at a liquid velocity of $0.15\left(\mathrm{~cm} \mathrm{~s}^{-1}\right)$ and for a $10 \mathrm{vol} . \%$ of $250 \mu \mathrm{m}$ size of the hydrophilic and $250 \mu \mathrm{m}$ size of hydrophobic sand. As can be shown in the plots, as the gas velocity raised, an enhancement in the spatial holdup of the gas occurred. However, beyond the homogeneous system, a slow divergence from the linear behavior was observed. Point of transference from homogeneous to turbulent flow has been examined from the profile of gas holdup at the column sections. Moreover, Figures 5, 6, and 7 show also the influence of axial distance on holdup of the gas. Within the homogenous mode, a proportional relation between the axial column height and the spatial holdup of the gas is shown, and this may be attributed to the energy of bubbles which has maxima at the zone of the gas distributor resulting in a higher bubble speed and so a minimum time of residence of bubbles in the column bottom section of the column was obtained leading to a lower spatial gas holdup. As gas velocity increased in the churn zone the generation rate of bubbles from gas distributor increases and more bubbles of small size per unit volume exist in the column bottom section which means higher holdup of gas compared to the bubbly regime. The effect of solid version on the stability of homogenous mode is shown in Figures 5, 6, and 7, and the inception of the transition zone in Figure 6 starts at lesser gas speed compared with that seen in Figure 6 . This may be attributed to bubble coalescence enhanced by the hydrophobic particles. Moreover, analysis of Figures 5, 6 and 7 shows that the particle diameter has an adverse consequence on the constancy of the bubbly flow system. In addition, Figures 5,6 , and 7 depict that the hydrophobic sand has more effect in reduction of the spatial holdup of the gas than the hydrophilic one. This could be due to adhesion of gas bubble on hydrophobic particles. This adhesion of air bubbles to the hydrophobic molecules causes a decrease in their density and consequently leads to their widespread in the liquid, which increases the volumetric fraction of the solid and a decrease in the volumetric fracture of gas in the liquid. The published literature (Armstrong et al., 1976) has supported this interpretation. The effect of particle diameter on average gas holdup is shown in Figure 7. Figure 7 depicts that the lesser the size of particle the lower the holdup of gas-phase. This may be credited to the fact that the presence of smaller particles has an enhancement effect on the bubble coalescence.

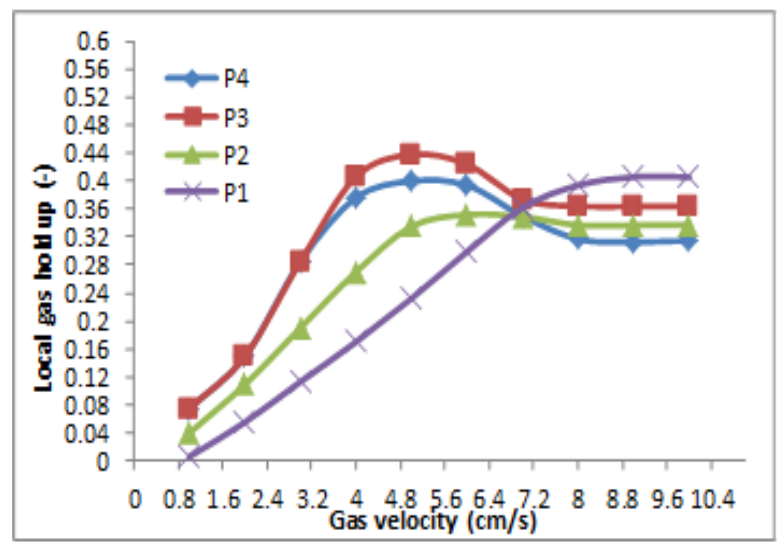

Figure5. Spatial gas holdup as a function of gas velocity for hydrophilic sand.

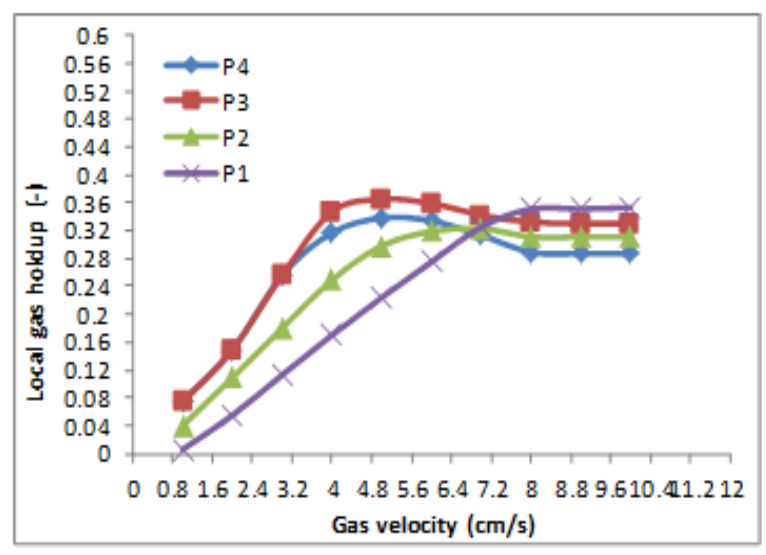

Figure 6. Spatial gas holdup as a function of gas velocity for hydrophobic sand. 


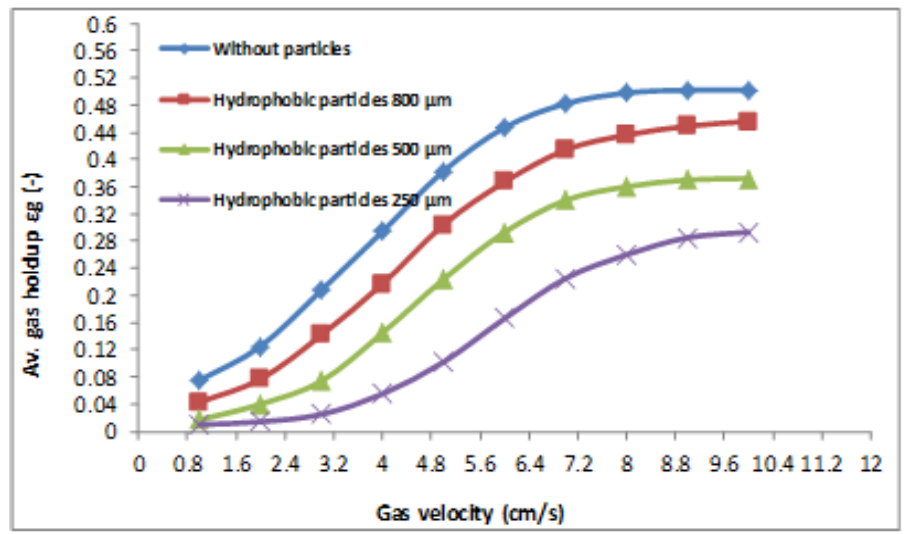

Figure7. Effect of gas velocity on average gas holdup with no particle, and 10 vol. \% of hydrophobic sand of size $(250 \mu \mathrm{m}, 500 \mu \mathrm{m}$, and $800 \mu \mathrm{m})$.

\section{AXIAL SOLID DISTRIBUTION}

Figures 8 and 9 illustrate the axial concentration profiles for $10 \%$ solid loading of (250) $\mu \mathrm{m}$ of hydrophilic and hydrophobic particles at gas velocity $U g=4 \mathrm{~cm} \mathrm{~s}^{-1}$ and at different liquid velocities respectively. It is shown in Figure 8 that the particles do not exist at the column bottom, and their loading profiles attain a maxima level that relies on the operating conditions. However, the axial profile of solid loading starts to decrease because of losing particle kinetic energy. Figure 9 plots the hydrophobic particles concentration axial profile. As can be shown in Figure 9, the axial profile is moving to upper scales in comparison with that of hydrophilic sand. This may be attributed to the reduction in the density of hydrophobic particles which promotes the ability to move higher more readily and crush, the foams of which occur at the upper part of the column.

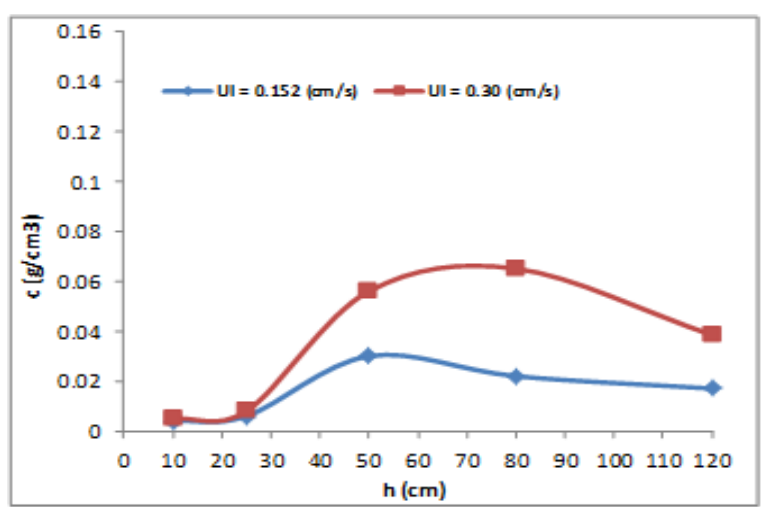

Figure 8. Effect of column height on the loading distribution of $10 \mathrm{vol} \%$ of $250 \mu \mathrm{m}$ hydrophilic sand at a constant gas velocity of $4 \mathrm{~cm} \mathrm{~s}^{-1}$.

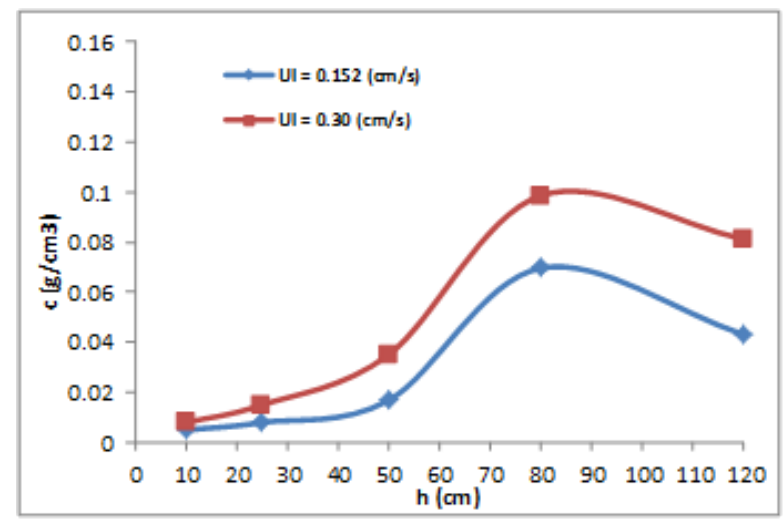

Figure 9. Effect of column height on the loading distribution of $10 \mathrm{vol} \%$ of $250 \mu \mathrm{m}$ hydrophobic sand at a constant gas velocity of $4 \mathrm{~cm} \mathrm{~s}^{-1}$. 


\section{DISTRIBUTION OFBUBBLE SIZE}

By using a photographic technique based on pictures of the bubbles taken at different heights $(\mathrm{Hs})=60,100$ and $160 \mathrm{~cm}$ of the column, from the bottom to the top, the diameter of the bubbles has been measured. A Sony (DSC-HX1) video camera was used to get the pictures. At least 20 definite bubbles at the chosen column height are used to estimate the regular dimension of the bubbles in the liquid state for the gas and liquid flow-rates applied. The Ai Adobe Illustrator CC (64 Bit) software is used to hold out the necessary capacity of the bubbles geometric specifications. Good quality images are then examined by the processing of the image to achieve the bubble sizes. The photographic technique used in the present paper for the bubble size was introduced in a prior study (Couvert et al., 1999; Sotiriadis et al., 2005). Figure 10 illustrates an instance of the snapshot in the cold ebullated bed column at $\mathrm{H}=100 \mathrm{~cm}$ for bubble size measurements using Ai Adobe Illustrator CC (64 Bit) software. The bubbles shaped in the column contain ellipsoidal form and for this cause, main (E) and subaltern (e) axes of the predictable ellipsoid have to be measured. The width of the corresponding sphere $(\mathrm{dB})$ calculated by Eq. 2, represents the average bubble size $d_{B}$ at each selected high of the EBR.

$d_{B}=\sqrt[3]{E^{2} \cdot e}$

Figure 11 shows the experimental results which depict the effect of gas and liquid flow-rates upon the bubble size generated in the ebullated bed column at $\mathrm{H}=100 \mathrm{~cm}$. As can be seen in Figure 11, as the gas rate increased, the number of bubbles also rises up in the gas sparger zone. As a result, the gas holdup enhanced. Furthermore, because the homogeneous system is maintained, there is a rise in the gas flow-rate, as well a rise in the bubble volume due to the low grade of coalescence. At a low liquid flow in the cold EBR with the soaring rate of the gas stream, a greater amount of bubbles shattered and then cohered. Consequently, a rise in the diameter of the bubbles occurred. As shown in Figure 11, the rate of increase of bubble diameter at higher liquid velocity ranges was less than that at lesser liquid speeds. A decrease in bubble diameter equal to $42 \%$ resulted at $\mathrm{Ul}=0.3 \mathrm{~cm} / \mathrm{s}$, while a reduction of $28 \%$ was obtained at $\mathrm{Ug}=0.15 \mathrm{~cm} / \mathrm{s}$. Photographs at different sections of the column with various gas and liquid stream speed are illustrated in Fig. 12(a), Fig. 12(b) and Fig. 12(c). Figure 12 shows the experimental results that depict the effect of gas flow-rates upon the bubble size generated in the ebullated bed column at different axial sections.

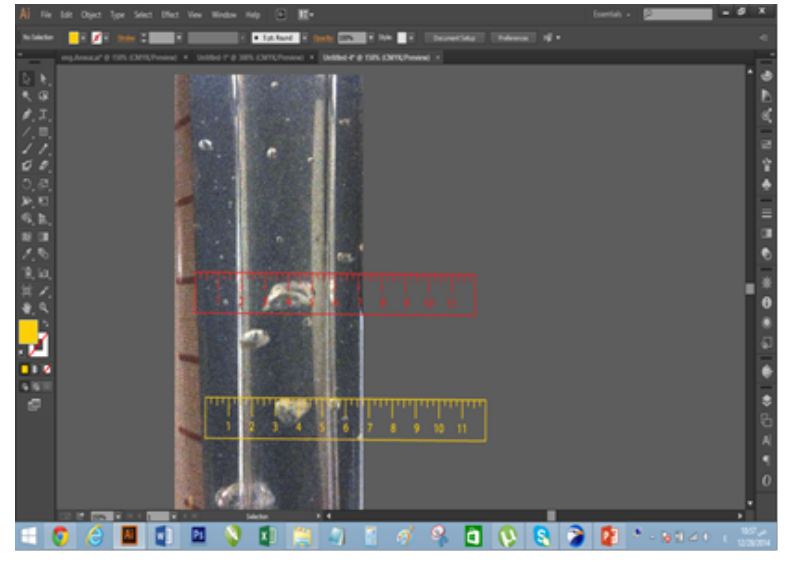

Figure 10. Snapshot of the column $(\mathrm{H}=100 \mathrm{~cm})$ using Ai Adobe Illustrator CC (64 Bit) software.

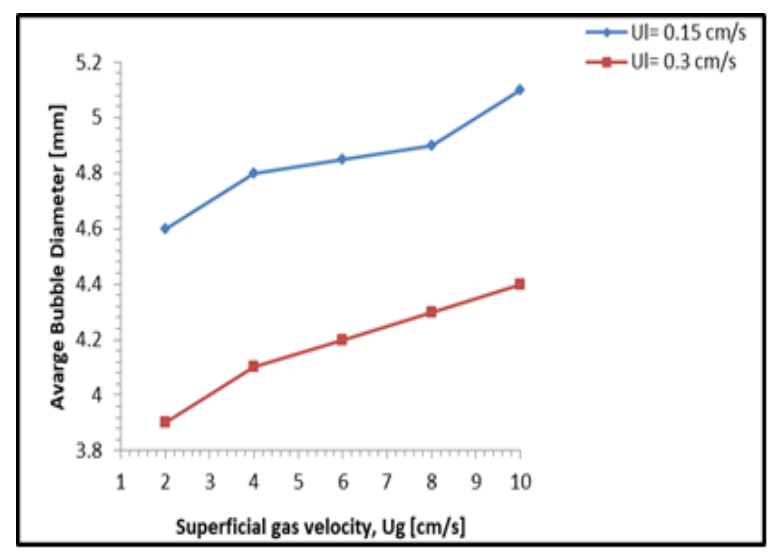

Figure 11. Effect of liquid velocity on average. bubble diameters at various gas velocities. 

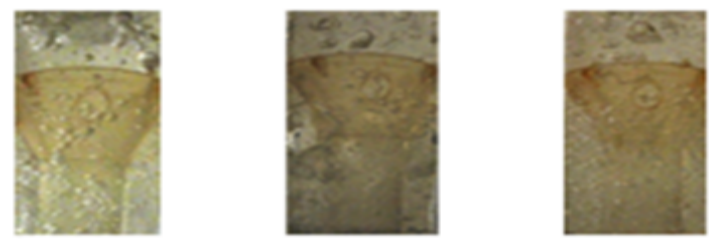

\title{
Height $160 \mathrm{~cm}$
}

Recycle cup Zone
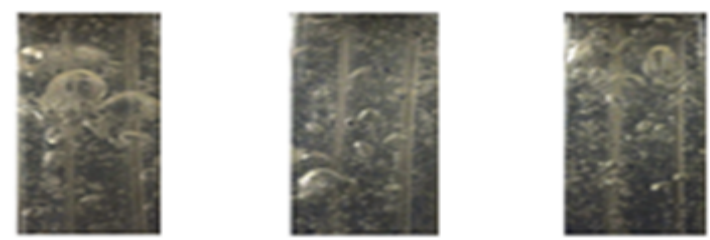

\author{
Height $100 \mathrm{~cm}$
}
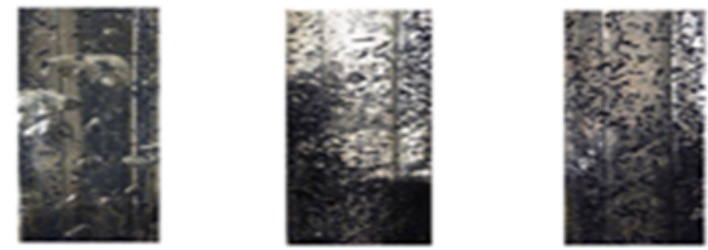

\section{Height $40 \mathrm{~cm}$}

Figure 12. Snapshots at different sections of the column and $(\mathrm{Ul}=0.15 \mathrm{~cm} / \mathrm{s}, \mathrm{R}=5)$ (a) $-\mathrm{Ug}=3 \mathrm{~cm} / \mathrm{s}$, (b) $-\mathrm{Ug}=4 \mathrm{~cm} / \mathrm{s}$, (c) $-\mathrm{Ug}=5 \mathrm{~cm} / \mathrm{s}$.

\section{FOAMING HINDERING}

Foaming is considered undesirable in the reactors used for hydro carbonaceous fluid processing because foaming reduces the space required for chemical conversion. It is well known that foams are formed by a physical mixing of solution water and a surfactant. The influence of particle hydrophobicity on foaming in a cold model of EBR is shown in Figures 13 and 14. Figure 13 shows the influence of different gas velocity and liquid velocity Ul= $0.15 \mathrm{~cm} \mathrm{~s}^{-1}$ on foam fraction using various volume percentages of $250 \mu \mathrm{m}$ particles of different sand versions in a $1 \mathrm{wt} \%$ butanol solution. The plots in Figure 13 reveal that nearly no foaming is generated at gas velocity up to $2 \mathrm{~cm}$ $\mathrm{s}^{-1}$. This phenomenon could be explained using Eq. 3 (Guitian and Joseph, 1998):

$$
\mathrm{Ug}=\mathrm{A}+\mathrm{B} \mathrm{Ul}
$$

where A and B are constants depending on foaming agent and gas sparger respectively. Guitian and Joseph (1998) introduced Eq.3 as the criteria of foaming. According to Eq. 3, no foaming occurred under certain values of $\mathrm{Ug}$ and Ul. It can be also observed in Figure 13 that as gas velocity increased foam fractions increase correspondingly. Moreover, Figure 13 plots the influence of the addition of different types of particles on the hindering of foaming during the operation of cold EBR. The average reduction in foam fraction, when operating at bubbly zone, attains about 0.65 and 0.78 using hydrophilic and hydrophobic respectively. Meanwhile in the churn flow zone the average reduction of foaming attains 0.5 and 0.66 respectively. This was attributed to the lower apparent density of hydrophobic particles which makes them readily reaching foams population at top of the column leading to crushing them. Figure 14 illustrates the influence of different gas velocity and $U \mathrm{l}=0.15 \mathrm{~cm} \mathrm{~s}^{-1}$ on foam fraction using various volume percentages of $250 \mu \mathrm{m}$ hydrophobic particles in a $1 \mathrm{wt} \%$ butanol solution. 


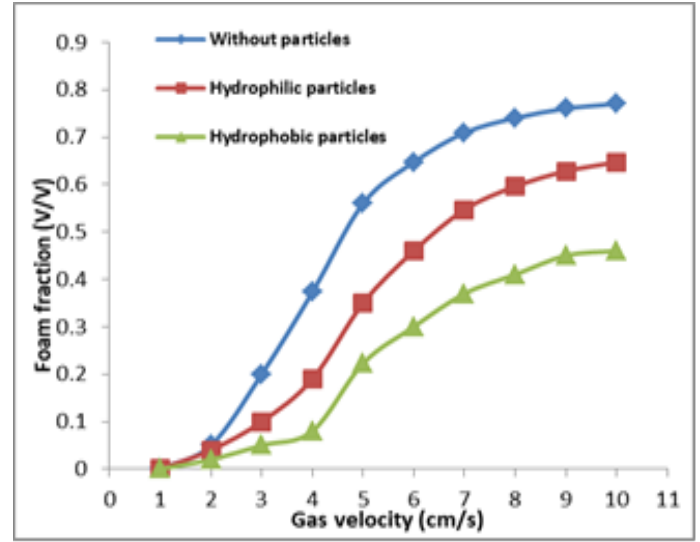

Figure 13. Influence of different gas velocity and $\mathrm{Ul}=0.15 \mathrm{~cm} \mathrm{~s}^{-1}$ on foam fraction for hydrophilic particles.

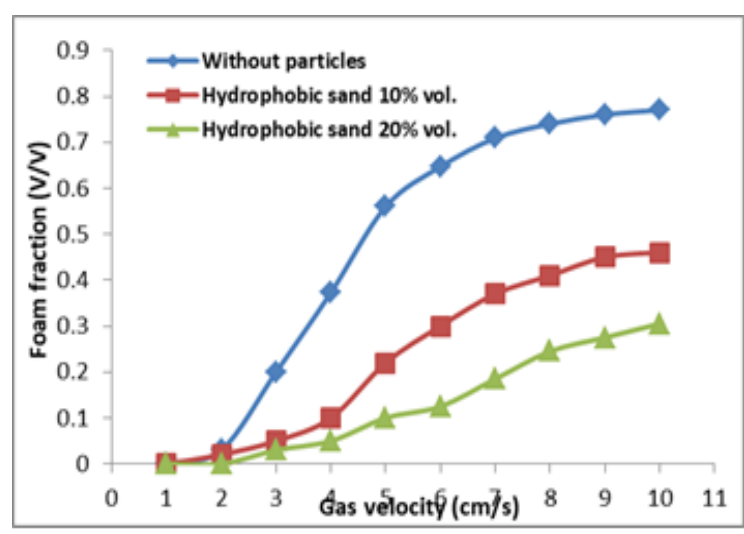

Figure 14. Influence of different gas velocity and $\mathrm{Ul}=0.15 \mathrm{~cm} \mathrm{~s}^{-1}$ on foam fraction for hydrophobic particles.

As can be shown in Figure 14, the maximum foaminess generated under studied operating variables (i.e., $\mathrm{Ug}=10$ $\mathrm{cm} \mathrm{s}^{-1}, \mathrm{Ul}=0.15 \mathrm{~cm} \mathrm{~s}^{-1}$, pressure $=1 \mathrm{bar}$, and $1 \mathrm{wt} \%$ butanol) is $0.77,0.54$, and 0.3 using 0,10 , and $20 \mathrm{vol} \%$ loading of hydrophobic particles respectively. Figure 13 depicts that hydrophobic particles of smaller size $(250 \mu \mathrm{rm})$ reduce foaming by $70 \%$ using 20 vol. $\%$ of solid loading. This may be attributed to the smaller size hydrophobic particles that infiltrate foams and being gathered at the foam interface resulting in liquid retaining. This mechanism as seen in Figure 14 is proportionally affected by solid loading in the EBR.

\section{CONCLUSION}

The hydrodynamics of ebullated- bed reactors (EBRs) which used in the H-Oil process, considered an effective key in the performance of the operating system. In the present work, the hydrodynamics in a lab-scale cold model ebullated bed column working under ambient conditions were studied, and the following have been concluded. $20 \mathrm{wt} . \% \mathrm{MgSO} 4$ solution could be used as the liquid phase to simulate the hydrodynamic behavior of the industrialscale EBR used for the heavy oil hydro-conversion process. Experimental results depicted that the transition from the homogenous to the heterogeneous regime is enhanced with decreasing particle diameter. Moreover, the degree of particle hydrophobicity was inversely proportional to the average gas holdup in the EBR. The reduction in average gas holdup was $7.9 \%$ using hydrophobic particles more than that of the hydrophilic particles. Studying the solid axial profile confirmed that the hydrophobic particles' apparent density leads to their widespread in the liquid, which increases the volumetric fraction of the solid and a decrease in the volumetric fraction of gas in the liquid. The effect of particle hydrophobicity on foaminess under different operating variables was investigated using $1 \mathrm{wt}$. $\%$ butanol solution. The experimental work revealed that hydrophobic particles of smaller size $(250 \mu \mathrm{rm})$ reduce foaming by $70 \%$ using 20 vol. \% of solid loading and gas and liquid velocities of 10 and $0.15 \mathrm{~cm} \mathrm{~s}^{-1}$ respectively. It was found that bubble sizes were increased with both gas velocity and the axial location far from the gas distributor while liquid velocity has negative impact on bubble size. The surface of catalyst particles can be modified to act as foaminess- reducer in fluidized bed hydro conversion reactors. 


\section{REFERENCES}

Abid, M. F., Ahmed, S. M., Al-Mously, H. H., \& Barghi D.S. 2019. Hydrodynamic Study of an Ebullated-bed Reactor in the H-oil Process. Iranian Journal of Science and Technology, Transactions A: Science, 43: 829838.

Andrew, S. P. S. 1982. Gas-Liquid Mass Transfer Microbiological Reactors, Trans. Inst. Chem. Eng., 60: 3-13.

Armstrong, E. R., Baker, C. G. J \& Bergougnou, M. A. 1976. Effects of Solids Wettability on the Characteristics of Three-phase Fluidization. Fluidization Technology, 127: 405.

Behkish, A., Men, Z., Inga, J. R. \& Morsi, B. I. 2002. Mass Transfer Characteristics in a Large-Scale Slurry Bubble Column with Organic Liquid Mixtures. Chem. Eng. Sci., 57: 3307.

Chaumat, H., Billet-Duquenne, A. M., Augier, F., Mathieu, C, \& Delmas, H. 2005. Mass Transfer in Bubble Column for Industrial Conditions - Effects of Organic Medium, Gas and Liquid Flow Rates and Column Design. Chem. Eng. Sci., 60: 5930.

Chilekar, V. P. 2007. Hydrodynamics and mass transfer in slurry bubble columns: scale and pressure effects, Eindhoven: Technische Universiteit Eindhoven. https://doi.org/10.6100/IR627023.

Chilekar, V.P., van der Schaaf, J., Ruud Van Ommen, J. \& Kuster, B. F. M. 2007. Effect of Particle Lyophobicity in Slurry Bubble Columns at Elevated Pressures. Chemical Engineering Science, 62(18): 5533-5537.

Couvert, A., Chatellier, P. \& Roustan, M. 1999. Two-Phase Hydrodynamic Study of a Rectangular Airlift Loop Reactor with an Internal Baffle. Chem. Eng. Sci., 54: 5245-5252.

El-Din, G. M. \& Smith, D. W. 2003. Measurement of size, rise velocity, and specific interfacial area of bubbles in an impinging jet bubble column. J. Environ. Eng. Sci., 2: 127-138.

Ghildyal, N. P., Lonsan, B. K. \& Karanth, N. G. 1988. Foam Control in Submerged Fermentation.Adv. Microbiol., 33: 173-222.

Guitian, J. \& Joseph, D. 1998. How Bubbly Mixtures Foam and Foam Control Using a Fluidized Bed. International Journal of Multiphase Flow, 24(1): 1-16.

Herbolzheimer, E., Bedminster, N. J. \& Iglesia, E. M. 2006. Slurry Bubble Column. Patent Number USRE39, $073 \mathrm{E}, \mathrm{CA}, \mathrm{USA}$.

Jordan, U. \& Schumpe, A. 2001. The Gas Density Effect on Mass Transfer in Bubble Columns with Organic Liquids. Chem. Eng. Sci., 56: 6267.

Koide, K., Yamazoe, S. \& Harada, S. 1985. Effects of Surface-Active Substances on Gas Hold-Up and GasLiquid Mass Transfer in Bubble Column. J. Chem. Eng. Japan, 18: 287-292.

Kressmann, S., Boyer, C., Colyar, J. J., Schweitzer, J. M. \& Viguiè, J. C. 2000. Improvements of EbullatedBed Technology for Upgrading Heavy Oils. Oil \&Gas Science and Technology- Rev. IFP, 55(4): 397-406.

Lang, C. 2002. Mass transfer in bubbly flows: Influence of physico-chemical and hydrodynamic conditions, In Gas Transfer at Water Surfaces. Geophys. Monogr. Ser., 127: 363-369.

Lau, R., Peng, W., Velazquez-Vargas, L. G., Yang, G. Q. \& Fan L S 2004. Gas-Liquid Mass Transfer in High-Pressure Bubble Columns. Ind. Eng. Chem. Res., 43: 1302.

Maloney, J. E. \& Oakes, T. R. 1984. Hydrophobic silica or silicate composition, patent number 4443357 in Apr. 17.

Martı'nez, J., Ancheyta, J., Ruiz, R. S. \& Sá nchez, J. L. 2010. A Review of Process Aspects and Modeling of Ebullated Bed Reactors for Hydrocracking of Heavy Oils1. Catalysis Reviews, 52: 60-105. 
Mata, C. \& Joseph, D. D. 1999. Foam control using a fluidized bed of hydrophobic particles. Int. J. Multiphase Flow, 25(1): 63-85.

Mersmann, A. 1978. Design and Scale-up of bubble and spray columns, Ger. Chem. Eng., 1: 1-11.

Pino, L. Z., Solari, R. B., Siuier, S., Estevez, L. A., Yepez, M. M. \& Saez, A. E. 1992. Effect of operating conditions on gas holdup in slurry bubble columns with a foaming liquid. Chem. Eng. Commun., 117: 367382.

Ruff, K., Pilhofer, T. \& Mersmann, A. 1976. Complete Flow through Perforated Bottoms during Fluid Dispersion. Chem. Ing. Tech., 48: 759-765.

Sada, E., Katoh, S. \& Yoshil, H. 1984. Performance of the gas-liquid bubble column in molten salt systems. Ind. Eng. Chem. Process Des. Dev., 23: 151-154.

Safoniuk, M. 1999. Dimensional Similitude and the Hydrodynamics of Three-Phase Fluidized Beds, PhD thesis, Department of Chemical and Bio-Resource Engineering, the University of British Columbia Vancouver, B.C., Canada.

Schweitzer, J. M. \& Kressmann, S. 2004. Ebullated Bed Reactor Modeling for Residue Conversion, Chem. Eng. Sci., 59: 5637-5645.

Sotiriadis, A. A., Smith, J. M. \& Thorpe, R. B. 2005. Bubble Size and Mass Transfer Characteristics of Sparged Downwards Two-Phase Flow. Chem. Eng. Sci., 60: 5917-5929.

Takesono, S., Onoodera, M., Yoshida, M. \& Yamagiwa, K. 2004. Performance Characteristics of a StirredTank Reactor with a Mechanical Foam-Breaker Utilizing Shear Force. J. Chem. Eng. Japan, 37(1): 14881496.

Vandu, C. O., Koop, K. \& Krishna, R. 2004. Volumetric Mass Transfer Coefficient in a Slurry Bubble Column operating in the Heterogeneous Flow Regime. Chem. Eng. Sci., 59: 5417.

Zhang, X. H. \& Shaw, J. M. 2006. Impact of Multiphase Behavior on Coke Deposition in Heavy Oils Hydro processing Catalysts, Energy \& Fuels, 20: 473-480. 